\title{
Computational analysis of solid particle-erosion produced by bottom ash slurry in $90^{\circ}$ elbow
}

\author{
Jashanpreet Singh ${ }^{1, *}$, Jatinder Pal Singh ${ }^{1}$, Mandeep Singh ${ }^{1}$, and Mirosław Szala ${ }^{2}$ \\ ${ }^{1}$ Thapar Institute of Engineering and Technology, Mechanical Engineering Department, Patiala, 147004, Punjab, India \\ ${ }^{2}$ Lublin University of Technology, Faculty of Mechanical Engineering, Nadbystrzycka 36, 20-618 Lublin, Poland
}

\begin{abstract}
Present work is devoted to investigation of the slurry erosion wear in a $90^{\circ}$ elbow by using commercial Computational fluid dynamics (CFD) code FLUENT. Discrete phase erosion wear model was used to predict erosion in $90^{\circ}$ elbow by solving the governing equations through Euler-Lagrange scheme. Particle tracking was considered by using standard $k-\varepsilon$ turbulence scheme for the flow of bottom ash slurry. Erosion wear in elbow was investigated along with velocity distribution and turbulence intensity. The radius-to-diameter $(r / D)$ ratio was taken as 1.5 . Results show that erosion rate increases with increase in velocity. Present numerical simulation model holds close agreement with previous studies. Distorted patterns appeared at low velocities. The V-shape pattern appeared on the outer wall of elbow at high velocities. The low velocity region occurs around circumference of elbow wall at outer wall of elbow due to stimulation of the drag forces near the wall region.
\end{abstract}

\section{Introduction}

Erosion wear is a commonly observed problem in many industries such as thermal power plants, mining industry, chemical industry, etc. [1-5]. In thermal power plants, the erosion wear (i.e. slurry erosion wear) problem is observed in ash disposal systems. Slurry erosion wear problem occurs due to collisions of solid particles that travel in a liquid while striking to target. Due to such problem, the pipeline circuit undergo serious damage at different components tees, elbows or reducers [3].

Many researchers had reported the slurry erosion wear investigation basing on an influence of various parameters such as fluid-flow behaviour, design and geometries, properties of pipeline material, a condition of the impact made by particles, particle movements, etc. [6-8]. According to many researchers, that mechanism of erosion wear for the solid-liquid media flow depends on fluid flow characteristics [9-12].

Researchers $[13,14]$ had reported that investigation based on pilot plant experimentation of slurry erosion wear are time consuming and expensive. From last two decades, fluid mechanics based problems have experienced a great progress/interest in an availability of low-cost highperformance computers $[11,17]$. Thus, it can be said that the CFD is a reliable way to predict flow behaviour and problems associated with the fluid flow faced by industrial and commercial sector.

In the present work, the erosion wear in the $90^{\circ}$ elbow was investigated by using commercial Computational fluid dynamics (CFD) code FLUENT. Discrete phase slurry erosion wear model was used to predict the erosion in the $90^{\circ}$ elbow by solving the governing equations through Euler-Lagrange scheme.
Particle tracking was performed by using standard $k-\varepsilon$ turbulence scheme for the flow of bottom ash slurry.

\section{Mathematical modelling}

The erosion wear, hereinafter referred to as erosion wear, problem for the bottom ash-slurry flow in $90^{\circ}$ elbow is solved by using the commercially available computational fluid dynamics (CFD) tool FLUENT. Flowing media was the liquid phase $(p)$ i.e. water whereas the discrete media was the solid phase $(q)$ i.e. bottom ash. Both of the phases were treated as incompressible in nature. Governing equations of both phases were solved by Time-averaged Navier-Stokes equation by applying the Two-way fluid particle coupling. Slurry was assumed as homogenous in nature at every point of mesh. Euler-Lagrange two-phase model was used to solve the governing equations of slurry flow in the $90^{\circ}$ elbow, which has been discussed as follows.

\subsection{Continuity equation}

The volumetric concentration of $p$ and $q$ phases was evaluated by applying the continuity equation, as written below:

$$
-\frac{\partial}{\partial \mathrm{t}}\left(a_{q} \rho_{q}\right)+\nabla\left(a_{p} \rho_{p} v_{p}\right)=\sum_{p=1}^{n}\left(\dot{m}_{q p}-\dot{m}_{p q}\right)
$$

In an equation illustrated above, $\dot{m}_{q p}$ refers to the mass transformation which occurs between $q$ and $p$ phase. The effective density of phase $q$ is denoted as:

$$
\vec{\rho}=a_{q} \rho_{q}
$$

\footnotetext{
*Corresponding author: jashanpreet.singh@thapar.edu
} 


\subsection{Momentum equations}

The governing equation to calculate the momentum of both phases is given below:

$$
\begin{gathered}
\frac{\partial}{\partial \mathrm{t}}\left(a_{p} \rho_{p} \vec{v}_{p}\right)+\nabla\left(a_{p} \rho_{p} \vec{v}_{p} \vec{v}_{p}\right)=-a_{p} \nabla_{b}+\nabla \overline{\bar{\tau}}_{p}+a_{p} \rho_{p} \vec{g}+K_{q p}\left(\vec{v}_{q}-\vec{v}_{p}\right) \\
\frac{\partial}{\partial \mathrm{t}}\left(a_{q} \rho_{q} \vec{v}_{q}\right)+\nabla\left(a_{q} \rho_{q} \vec{v}_{q} \vec{v}_{q}\right)=-a_{q} \nabla_{b}-a_{p} \nabla b_{q}+\nabla \overline{\bar{\tau}}_{q}+a_{q} \rho_{q} \vec{g}+K_{q p}\left(\vec{v}_{p}-\vec{v}_{q}\right)
\end{gathered}
$$

Where,

$$
p_{q}=a_{q} \rho_{q} \theta_{q}+2 \rho_{q}\left(1+e_{q q}\right) \times a_{q}^{2} \cdot g_{o, q q} \cdot \theta_{q q}
$$

The intermolecular collision $\left(g_{O, q q}\right)$ between grains of the solid particles is given by:

$$
g_{o, q q}=\left[1-\left(\frac{a_{x}}{a_{x, \max }}\right)^{\frac{1}{3}}\right]^{-1}
$$

The phase tensors for $q$ and $p$ are written below:

$$
\begin{gathered}
\overline{\bar{\tau}}_{q}=a_{q} \mu_{q}\left(\nabla \vec{\vartheta}_{q}+\nabla \vec{\vartheta}_{q}^{t r}\right)+a_{q}\left(\lambda_{q}-\frac{2}{3} \mu_{p}\right) \nabla \vec{\vartheta}_{q} \\
\overline{\bar{\tau}}_{p}=a_{p} \mu_{p}\left(\nabla \vec{\vartheta}_{q}+\nabla \vec{\vartheta}_{p}^{t r}\right)
\end{gathered}
$$

The solid-liquid exchange coefficient are given by:

$$
K_{p q}=150 \frac{a_{q}\left(1+a_{p}\right) \mu_{p}}{a_{p} d^{2} q}+1.75 \frac{\rho_{p} a_{q}\left|\vec{v}_{q}-\vec{v}_{p}\right|}{d_{q}} \quad\left\{K_{q p}=K_{p q}\right\}
$$

The bulk viscosity $\left(\lambda_{q}\right)$ between phase $q$ is given by:

$$
\lambda_{q}=\frac{4}{3} a_{q} \rho_{q} d_{q} g_{o, q q}\left(1+e_{q q}\right) \times\left(\frac{\theta_{q}}{\pi}\right)^{\frac{1}{2}}
$$

The shear viscosity $\left(\mu_{q}\right)$ of phase $q$ is given by [11]:

$$
\mu_{q}=\mu_{q, c o l}+\mu_{q, k i n}+\mu_{q, b u l k}
$$

Where,

$$
\begin{aligned}
& \mu_{q, c o l}=\frac{4}{5} a_{q} \rho_{q} d_{q} g_{o, q q}\left(1+e_{q q}\right) \times\left(\frac{\theta_{q}}{\pi}\right)^{\frac{1}{2}} \\
& \mu_{q, k i n}=\frac{10 \rho_{q} d_{q} \sqrt{\theta_{q} \pi}}{96 a_{q}\left(1+e_{q q}\right) g_{o, q q}}+\left[a_{q} \rho_{q} d_{q} g_{o, q q}\left(1+e_{q q}\right)\right]^{2} a_{D}
\end{aligned}
$$

$$
\mu_{q, b u l k}=\frac{P_{q} \sin \varphi}{2 \sqrt{I_{2 q}}}
$$

Terms $\mu_{q, k i n} \mu_{q, c o l}$, and $\mu_{q, b u l k}$ denotes collisional, kinetic and bulk viscosities of phase $q$.

\subsection{Particle tracking model}

Phase $q$ flowing in phase $p$ is tracked with help of standard $k-\varepsilon$ turbulence model. The values of coefficients in standard $k-\varepsilon$ turbulence model are given as follows:

$-C_{1 \varepsilon}=1.44, C_{2 \varepsilon}=1.92, C_{\mu}=0.09, \sigma_{k}=1.00$, and $\sigma_{\varepsilon}$ $=1.30$.

- The randomness occur in phase $q$ due to turbulences encountered by using a stochastic scheme.

- The mean flow velocity of phase $q$ is given by:

$$
v_{q}=\bar{v}_{q}+v_{q}^{\prime}
$$

Lagrangian frame integrally solves the force-balance equation to track the trajectories of particles. Forcebalance equation is given by:

$$
\frac{\partial u_{q}}{\partial t}=F_{q}\left(v_{p}-v_{q}\right)+\frac{g\left(\rho_{p}-\rho_{q}\right)}{\rho_{q}}+F_{D g}
$$

The drag force $\left(F_{D g}\right)$ is calculated by:

$$
F_{D g}=\frac{18 \mu_{p}}{\rho_{q} d_{q}^{2}} \times \frac{C_{D g} \operatorname{Re}}{24}
$$

The value of Reynolds number $(R e)$ for the flow of solid-liquid media is given as:

$$
\operatorname{Re}=\frac{\rho_{f} d_{q}\left|v_{q}-v_{p}\right|}{\mu_{p}}
$$

\subsection{Erosion wear model}

Various models were used in earlier studies to predict the erosion wear in pipelines. However, researchers [5, 16] reported that the discrete phase model (DPM) is most suitable to problem related to erosion wear. The erosion wear equation solved by DPM model is given below :

$$
E_{r}=\frac{\sum_{p=1}^{n} m_{q} C\left(d_{q}\right) \cdot f(\alpha) \cdot v_{p}^{b\left(v_{p}\right)}}{A_{\text {face }}}
$$

The value constant terms are given as: $b=1.8 \times 10^{-9}, f=$ 1 , and $C=0[17]$. 


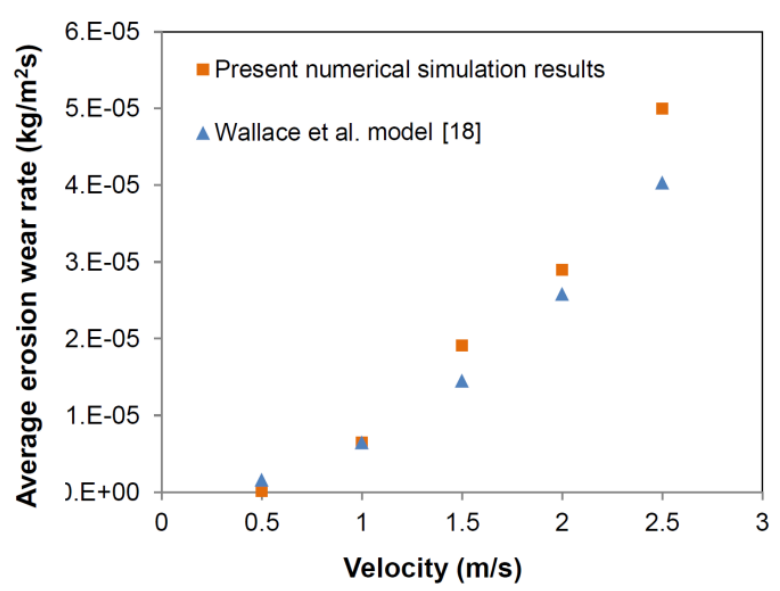

Fig. 1. Validation of numerical model.

\subsection{Validation of numerical model}

Fig. 5 shows comparative analysis between the present simulation results and analytical results obtained from reported by Wallace et al. [18] model. Simulation conditions were matched with analytical conditions by applying the velocity from 0.5 to $2.5 \mathrm{~m} / \mathrm{s}$. Wallace et al. [18] model is given below:

$E=\frac{\frac{1}{2} V_{f}^{2} \cos ^{2} \alpha \times \sin 2 \alpha}{\gamma}+\frac{\frac{1}{2} V_{f}^{2} \sin ^{2} \alpha}{\sigma} \quad\left\{\alpha \leq 18.5^{\circ}\right\}$

$E=\frac{\frac{1}{2} V_{f}^{2} \sin ^{2} \alpha}{\gamma}+\frac{\frac{1}{2} V_{f}^{2} \cos ^{2} \alpha}{\sigma}$

The values of coefficients in above equations are given below:

- Cutting wear coefficient, $\gamma: 33,316.9$

- Deformation wear coefficient, $\sigma: 77,419.7$.

A close agreement was observed by comparative analysis between the present numerical simulation model and Wallace et al. [18] model. Present results holds $\pm 3.59 \%$ standard deviation from analytical results.

\section{NUMERICAL SIMULATION}

The modelling of the pipe geometry was done in commercial ANSYS R15.0. Fig. 2 shows schematic diagram of pipe bend geometry. The length of pipeline was extended to $1500 \mathrm{~mm}$ both sides of bend geometry so as to have fully developed flow. The slurry consists of bottom ash as solid phase and water as liquid phase. The input parameters used in CFD code are given below:

- Pipe diameter $=100 \mathrm{~mm}$

$-\mathrm{r} / \mathrm{D}$ ratio $=1.5$

- Pipe material $=$ mild steel

- Density of pipe material: $7850 \mathrm{~kg} / \mathrm{m}^{3}$

- Velocity of mixture $=2-5 \mathrm{~m} / \mathrm{s}$

- Volumetric fraction of solid phase $=0.01$

- Density of solid particles $=2200 \mathrm{~kg} / \mathrm{m}^{3}$

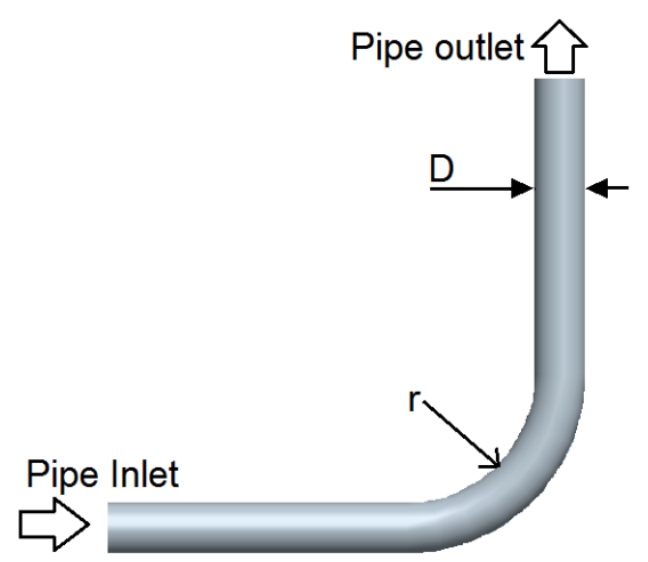

Fig. 2. Schematic diagram of pipe bend geometry.

Numerical simulations were carried out on Windows based Intel Xenon E51607v2 3.0 machine. The pipe geometry was discretised into tetrahedral mesh as shown in Fig. 3. The mesh size was taken as 2, 3, 4, and $5 \mathrm{~mm}$ that discretised the geometry into 458843, 458713, 457839 and 456579 number of elements. Solid particles of bottom ash were injected with water at inlet section of the pipeline. The total number of particles injected were $10^{4}$. The geometry of the pipeline was employed with three boundary conditions i.e. no slip condition at pipe wall, flow velocity at inlet section and pressure at outlet section. The boundary condition at the inlet section was applied to obtain fully developed flow, velocity contours and volume fraction profiles. The surface irregularities in the pipe materials were considered by taking the surface roughness as $0.5 \mathrm{~mm}$. The SIMPLEC algorithm coupled with pressure velocity was adapted to carryout simulation results. The values of various parameters used in discrete phase model analysis are listed below: - Injection: Inlet surface.
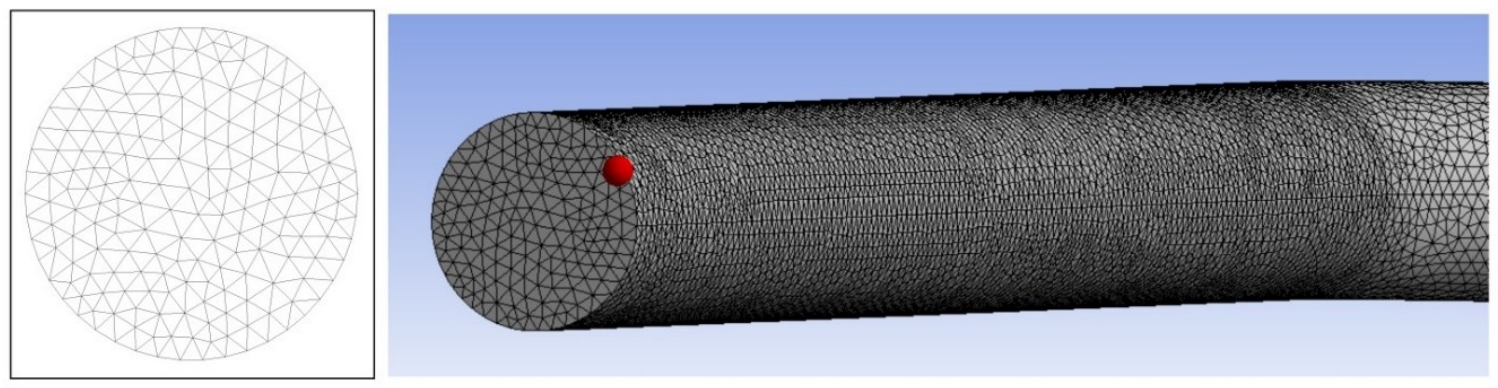

Fig. 3. Tetrahedral mesh for $90^{\circ}$ elbow. 
- Normal reflection coefficients: 0.993, -0.0307, $4.75 \times 10^{-4}$, and $-2.61 \times 10^{-6}$.

- Tangential reflection coefficients: $0.998,-0.029$, $6.43 \times 10^{-4}$, and $-3.56 \times 10^{-6}$.

- Velocity function : 2.6 .

- Diameter function: $1.8 \times 10^{-9}$.

- Convergence criteria: $10^{-4}$.

- Impact angle function: piecewise linear profile.

- Total points in piecewise linear: $9(0,0.8,1,0.5,0.4$, $0.5,1.0,0.8$, and 0 for impact angle of $0^{\circ}, 20^{\circ}, 30^{\circ}$, $45^{\circ}, 90^{\circ}, 135^{\circ}, 150^{\circ}, 160^{\circ}$, and $180^{\circ}$ respectively).

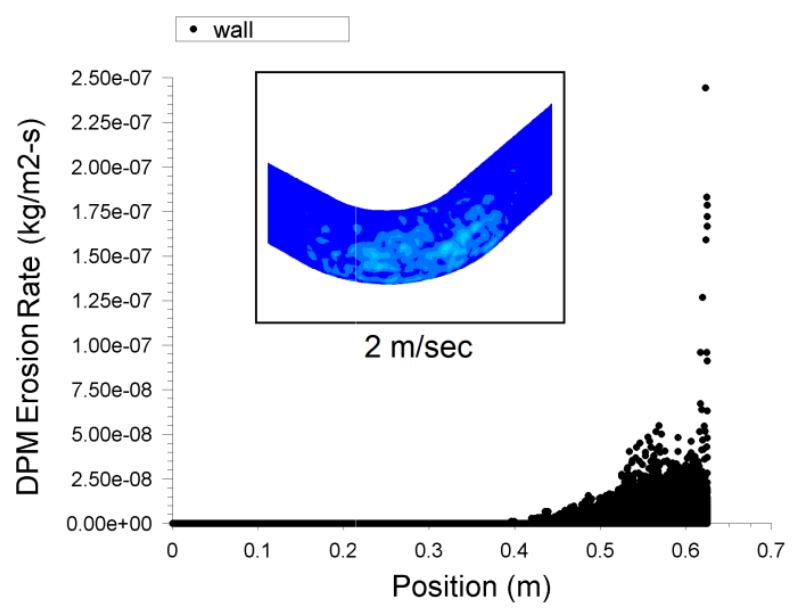

Fig. 4. Erosion wear distribution in elbow at $V=2 \mathrm{~m} / \mathrm{s}$.

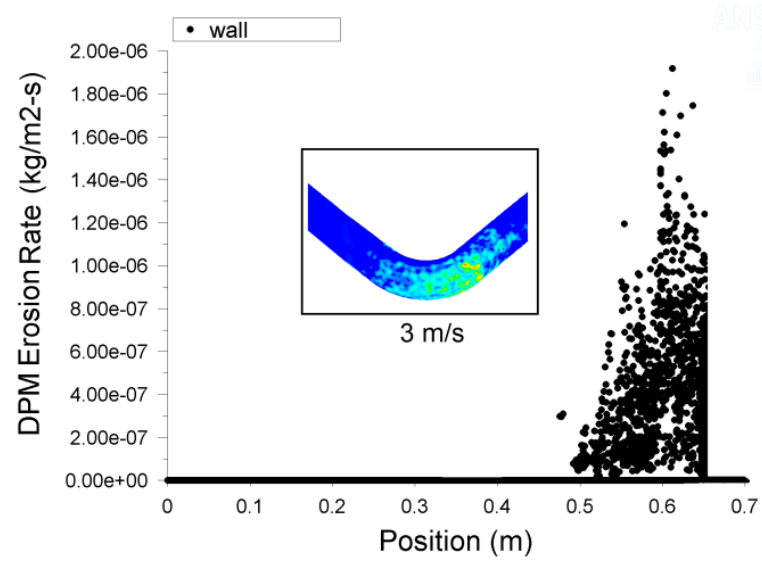

Fig. 5. Erosion wear distribution in elbow at $V=3 \mathrm{~m} / \mathrm{s}$.

\section{RESULTS AND DISCUSSION}

\subsection{Erosion wear in elbow wall}

Erosion wear rate is investigated in the $90^{\circ}$ elbow at different flow velocities. The diameter of pipe is kept constant i.e. $100 \mathrm{~mm}$ during the simulations. The $r / D$ ratio for the elbow was taken as 1.5 as suggested in previous studies. The sieve analysis experiments are conducted to evaluate the weighted mean diameter. The weighted mean diameter of slurry is found as $162 \mu \mathrm{m}$. Fig. 4 represents the erosion wear rate in at flow velocity (v) of $2 \mathrm{~m} / \mathrm{s}$. The maximum erosion wear magnitude is found as $2.47 \times 10^{-7} \mathrm{~kg} / \mathrm{m}^{2} \mathrm{~s}$ at outer lower wall of the elbow. Erosion wear rate in at flow velocity $(v)$ of $3 \mathrm{~m} / \mathrm{s}$ is shown in Fig. 5. The erosion wear magnitude slightly increases with increase in low velocity. The maximum erosion wear is found as $1.91 \times 10^{-6} \mathrm{~kg} / \mathrm{m}^{2} \mathrm{~s}$.

Fig. 6 represents the erosion wear distribution at flow velocity of $4 \mathrm{~m} / \mathrm{s}$. The maximum erosion wear is found as $3.89 \times 10^{-6} \mathrm{~kg} / \mathrm{m}^{2} \mathrm{~s}$. The erosion wear pattern seems to change with increase in velocity from 3 to $4 \mathrm{~m} / \mathrm{s}$. The highest magnitude of erosion wear at $V=5 \mathrm{~m} / \mathrm{s}$ is $7.31 \times 10^{-6} \mathrm{~kg} / \mathrm{m}^{2} \mathrm{~s}$.

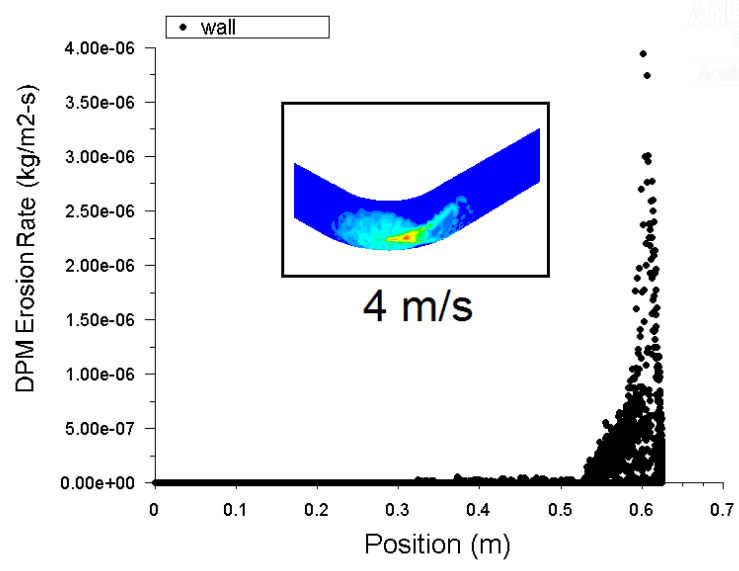

Fig. 6. Erosion wear distribution in elbow at $V=4 \mathrm{~m} / \mathrm{s}$.

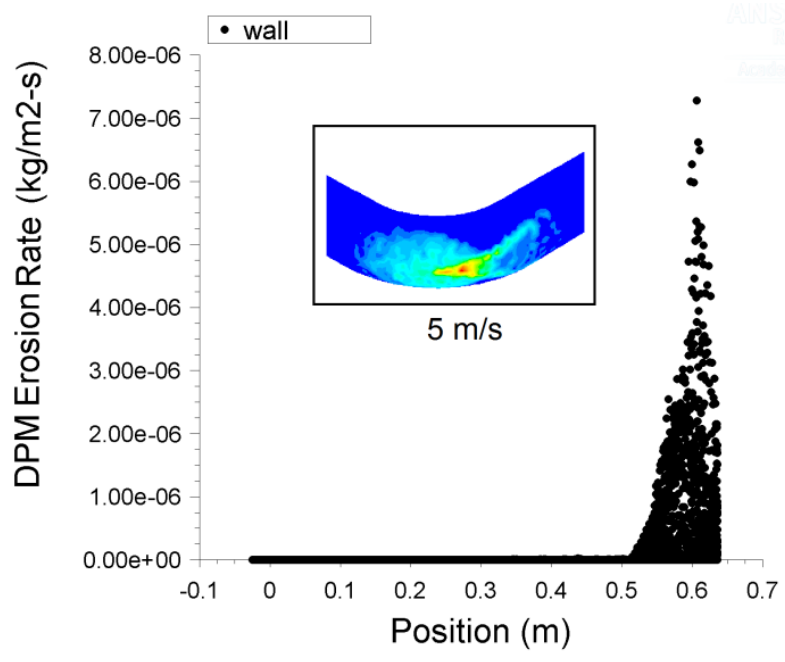

Fig. 7. Erosion wear distribution in elbow at $V=5 \mathrm{~m} / \mathrm{s}$.

\subsection{Erosion wear distribution in elbow}

Erosion distributions in the $90^{\circ}$ elbow at different velocities is shows in Fig. 8. Erosion wear was a pattern change as the velocity changes. Distorted patterns occur at low velocities (i.e. 2 and $3 \mathrm{~m} / \mathrm{s}$ ). A V-shape pattern appeared on the outer wall of the elbow at high velocities. Similar type of pattern was observed at flow velocity of 5 $\mathrm{m} / \mathrm{s}$. This happens due to fact that bottom ash particles move at low kinetic energies at low velocities [19, 20]. Lower kinetic energies generate lower magnitude forces which result in lower magnitude on the elbow wall. On the other hand, the bottom ash particles exert high kinetic energies which results in higher magnitude of force transfer between particles and elbow wall thus, high erosion wear occurs. Similar phenomenon was also observed in previous studies $[3,5,14]$. 


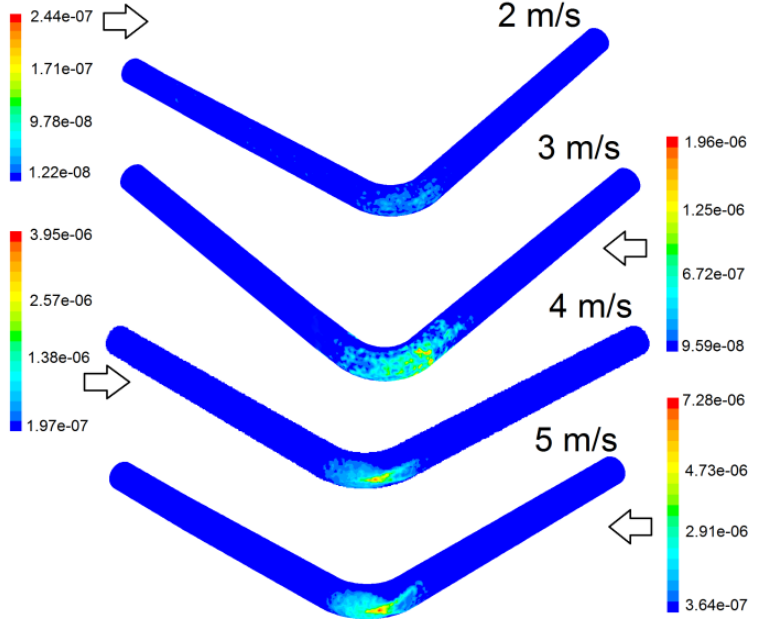

Fig. 8. Erosion distribution in the $90^{\circ}$ elbow.

\subsection{Velocity distribution in the elbow}

Fig. 9 shows the distributions of velocity vectors in the $100 \mathrm{~mm}$ diameter elbow at velocity of $5 \mathrm{~m} / \mathrm{s}$. The $\mathrm{r} / \mathrm{D}$ ratio for the elbow was taken as 1.5. The weighted mean diameter and solid concentration of slurry is taken as 162 $\mu \mathrm{m}$ and $60 \%$ (by weight) respectively. A low-velocity region forms at outer wall of elbow as illustrated in Fig. 9. Fig. 10 illustrates the $x-y$ plot of velocity distribution at outlet section of the elbow diameter.

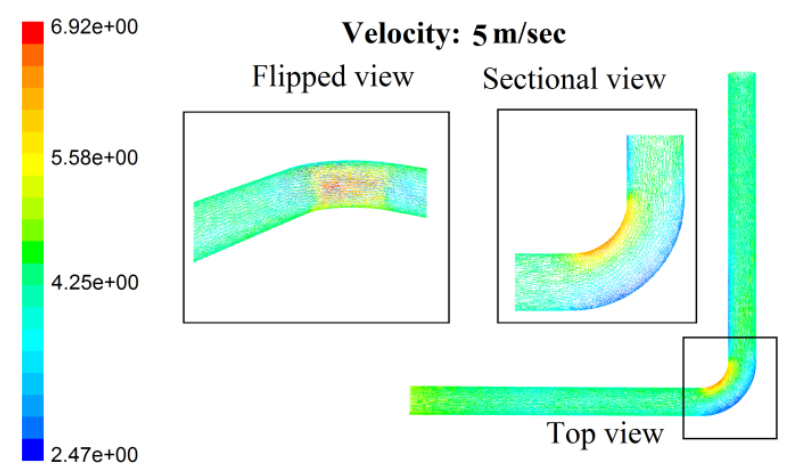

Fig. 9. Distribution of velocity vectors in the $90^{\circ}$ elbow.

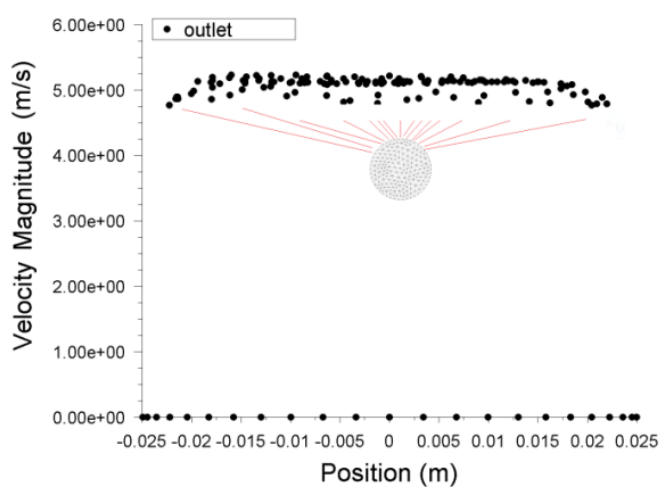

Fig. 10. Distribution around circumference of the $90^{\circ}$ elbow.

Fig. 11 represents velocity contours at various positions of the $90^{\circ}$ elbow at different velocities. It is observed that high velocity region occurs nearby the inner wall of the elbow. The magnitude of velocity is found maximum at the inner wall of the elbow at angle of $45^{\circ}$. As fluid moves above $45^{\circ}$, the velocity magnitude starts dropping and becomes concentric at $90^{\circ}$. The velocity region becomes almost same at the central region of the elbow while travelling to pipe outlet. Another observation indicates that the low velocity region occurs around circumference of the elbow wall. This happens due to stimulation of the drag forces near the wall region.
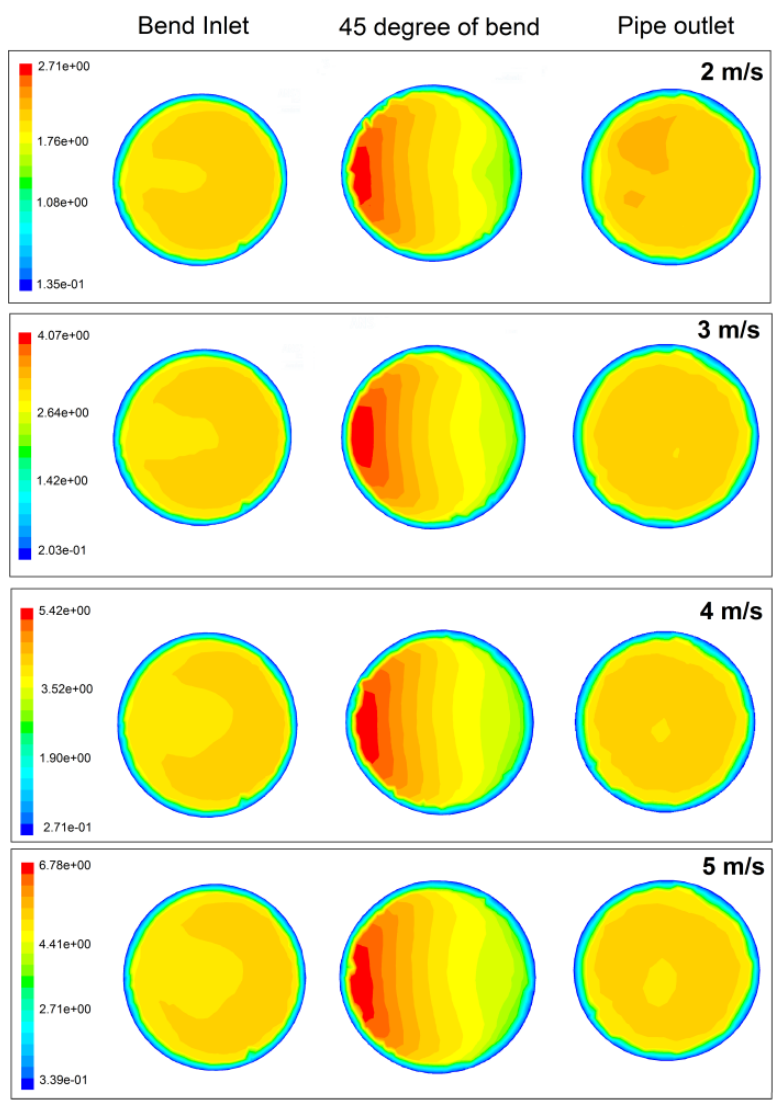

Fig. 11. Velocity contours at various positions of the $90^{\circ}$ elbow.

\subsection{Turbulence intensity in the elbow}

Turbulence intensity is also crucial for erosion wear of elbows. Turbulence induces the randomness in path of particles travelling in an elbow. This randomness in path of particles results in more localise attacks of flowing particles with elbow wall. During the numerical simulations, it was found that the turbulence intensity increases with increase in velocity. Fig. 12 represents the turbulence intensity contours and $x-y$ plots for the $90^{\circ}$ elbow. Low turbulence region occurs at the outer wall of the elbow whereas the high turbulence region occurs nearby the inner wall. However, the turbulence was found negligible at entrance of the elbow (i.e. bend inlet). The $x-y$ plot confirms above statement. In $x-y$ turbulence plot, the magnitude of turbulence intensity is found maximum at $0.575 \mathrm{~m}$ that represents the mid of the elbow. The turbulence intensity is also investigated at various positions of the elbow and the pipe. Fig. 13 depicts that turbulence intensity attains its maximum magnitude as its curvature angle approaches to $45^{\circ}$ [21]. Turbulence intensity remains unaffected at the outer wall of the elbow. Turbulence intensity remains low at the central point of pipe outlet. 


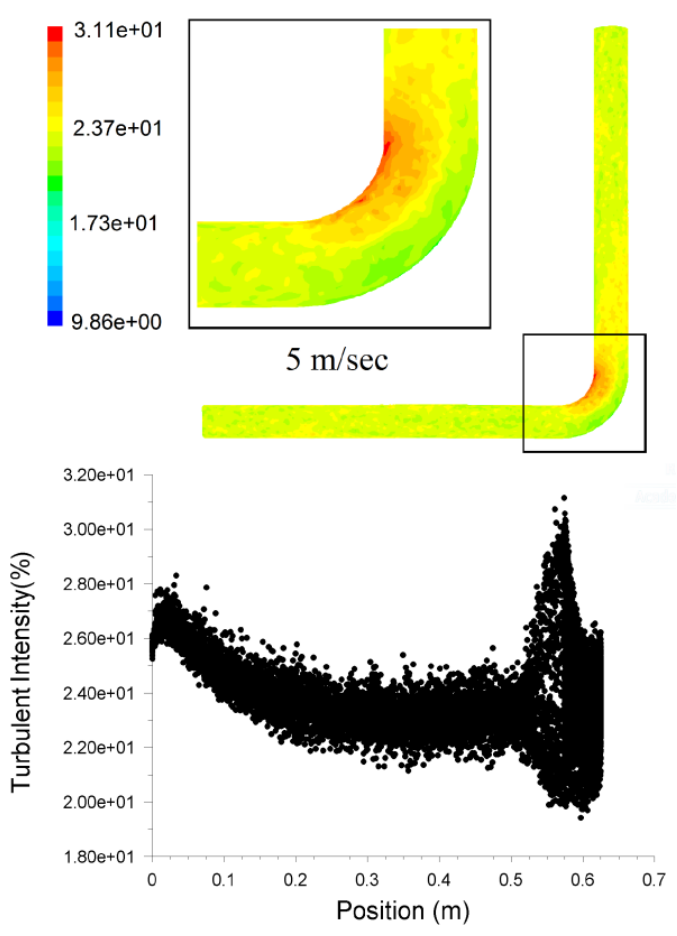

Fig. 12. Turbulence intensity distribution for the $90^{\circ}$ elbow.

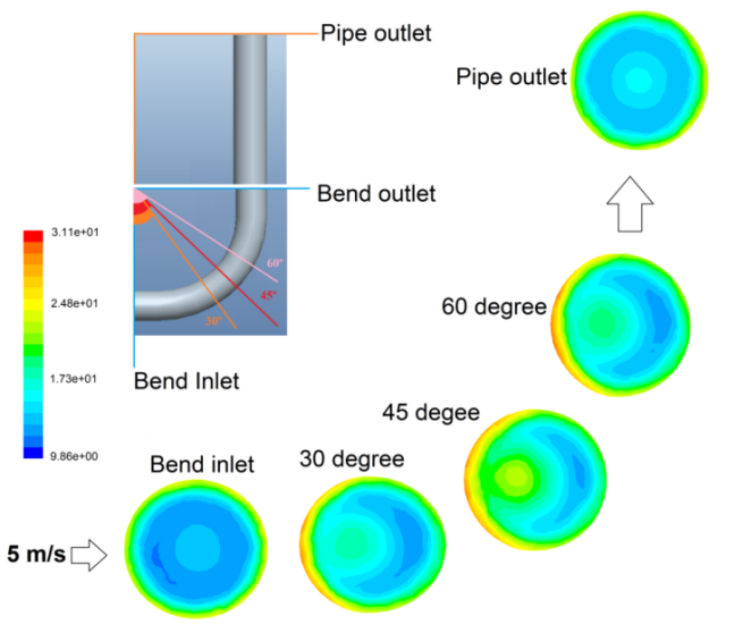

Fig. 13. Turbulence intensity contours at various positions of the elbow and pipe.

\section{CONCLUSION}

Present work was is devoted to investigation of the slurry erosion wear in the $90^{\circ}$ elbow by using commercial Computational fluid dynamics (CFD) code FLUENT. Discrete phase erosion wear model was used to predict the erosion in that elbow by solving the governing equations through Euler-Lagrange scheme with standard $k-\varepsilon$ turbulence scheme. It can be concluded that:

- Erosion rate varies increases with increase in velocity.

- Distorted patterns appeared at low velocities. The $\mathrm{V}$-shape pattern appeared on the outer wall of elbow at high velocities.

- The low-velocity region forms at outer wall of elbow.

- The low velocity region occurs around circumference of elbow wall. This happens due to stimulation of the drag forces near the wall region.
- Turbulence intensity attains its maximum magnitude as its curvature angle approaches to $45^{\circ}$.

- Turbulence intensity remains unaffected at outer wall of elbow. It remains low at central point of pipe outlet.

\section{References}

1. J. Singh, S. Kumar, S.K. Mohapatra, Wear 377, 1105 (2017).

2. Q.H. Mazumder, S.A. Shirazi, B. McLaury, J. Press. Vessel. Technol. 130(1), 11303/1 (2008).

3. J. Singh, S. Kumar, J.P. Singh, P. Kumar, S.K. Mohapatra, Particul. Sci. Technol. (accepted) https://doi.org/10.1080/02726351.2017.1364816

4. M. Szala, L. Daniel, J. Technol. Exploit. Mech. Eng. 2(1), 40 (2016).

5. M. Szala, T. Hejwowski, Coatings. 8, 254 (2018)

6. L.L. Parent, D.Y. Li, Wear 301, 477 (2013).

7. C.I. Walker, M. Hambe, Wear 332, 1021 (2015).

8. K. Nandakumar, K. Ekambara, R. Sanders, Ind. Eng. Chem. Res. 48, 8159 (2009).

9. J.P. Singh, S. Kumar, S.K. Mohapatra, J. Coal Prep. Util. (accepted) https://doi.org/10.1080/19392699.2018.1488693

10. J.P. Singh, S. Kumar, S.K. Mohapatra, J, Coal Prep. Util. (accepted) https://doi.org/10.1080/19392699.2017.1415892

11. Duan Y., L. Chen, W. Pu, C. Zhao, Korean J. Chem. Eng. 26(4), 1144 (2009).

12. H. Arabnejad, S.A. Shirazi, B.S. McLaury, et al. Wear 332-333, 1098 (2015).

13. S.K. Li, J.A.C. Humphrey, A.V. Levy, Wear 173, 295 (1981).

14. W. Tsai, J.A.C. Humphrey, I. Cornet, A.V. Levy, Wear 68, 289 (1981).

15. C.B. Solnordal, C.Y. Wong, J. Boulanger, Wear 336, 43 (2015).

16. B. Bozzini, M.E. Ricotti, M. Boniardi, C. Mele, Wear 255, 237 (2003).

17. K. Ahlert, MS Thesis, The University of Tulsa, (1994).

18. M.S., Wallace, J.S. Peters, T.J. Scanlon, W.M. Dempster, S. McCulloch, and J.B. Ogilvie, Proceed. 2000 ASME Fluid. Eng. Summer Meeting, Boston. U.S.A. (2000).

19. K. Kumar, S. Kumar, G. Singh, J. Singh, J.P. Singh, Coatings 7(4), 54 (2017).

20. J. Singh, S. Kumar, S.K. Mohapatra, Tribol. Int. (accepted)

https://doi.org/10.1016/j.triboint.2018.06.004

21. J.P. Singh, S. Kumar, S.K. Mohapatra, Int. J. Hydrogen Energ. 42(31), 20133 (2017). 